\title{
The use (or rather the non-use) of cost-effectiveness data in priority setting decisions - are we underestimating the barriers to using health economics in real world priority setting decisions?
}

\author{
Comment on "Use of cost-effectiveness data in priority setting decisions: experiences from \\ the national guidelines for heart diseases in Sweden"
}

\section{Sandra T. Erntoft ${ }^{*}$}

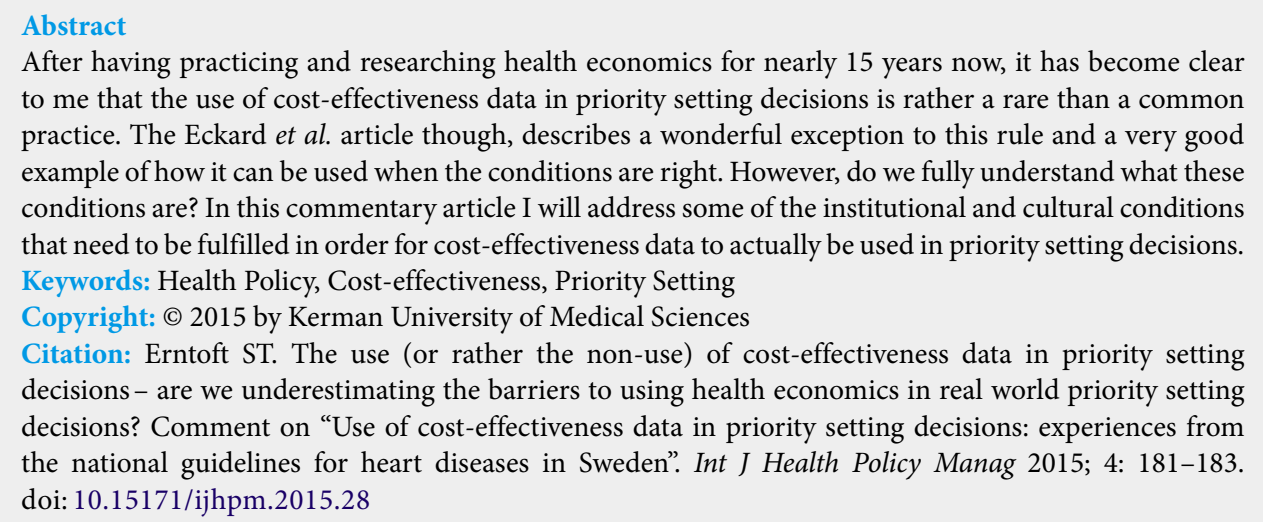

After having practicing and researching health economics for nearly 15 years now, it has become clear to me that the use of cost-effectiveness data in priority setting decisions is rather a rare than a common practice. The Eckard et al. article though, describes a wonderful exception to this rule and a very good example of how it can be used when the conditions are right. However, do we fully understand what these conditions are? In this commentary article I will address some of the institutional and cultural conditions that need to be fulfilled in order for cost-effectiveness data to actually be used in priority setting decisions. Keywords: Health Policy, Cost-effectiveness, Priority Setting

Copyright: @ 2015 by Kerman University of Medical Sciences

Citation: Erntoft ST. The use (or rather the non-use) of cost-effectiveness data in priority setting decisions - are we underestimating the barriers to using health economics in real world priority setting decisions? Comment on "Use of cost-effectiveness data in priority setting decisions: experiences from the national guidelines for heart diseases in Sweden". Int J Health Policy Manag 2015; 4: 181-183. doi: $10.15171 /$ ijhpm.2015.28

\section{Article History:}

Received: 22 January 2015 Accepted: 6 February 2015 ePublished: 10 February 2015

\section{Introduction}

Despite the large production of cost-effectiveness data worldwide, today it is fascinating that we know and understand so little about the actual use of health economic evaluations among the intended audience - the medical decision-makers. What happens after a health economic evaluation has been produced? Will it be used at all and, if so, how? Who uses economic evaluations and for what purposes? Are there differences in the use patterns between decision-makers at different healthcare levels? Are decision-makers able and willing to use them, and to what extent can the patterns be explained by contextual issues?

Quite a few researchers have tried to address these questions in systematic literature reviews (1-10) over time. All reviews conclude that a health economic evaluation seldom is the decisive factor behind decision at regional or local level but sometimes on a national level. Whether the technology (predominately pharmaceuticals) should be reimbursed or recommended or not is decided by an independent committee and many times done in an explicit way (11). These reviews indicate that health economic evaluations primarily are used as grounds for decisions on reimbursement status or treatment guidance at a national level, and often in connection with authorities' assessment of current and new technology in healthcare, like in the case provided by Eckard et al. (12). Yet, the great majority of priority setting decisions is taking place at the regional and local level under less formalized conditions.

Having studied real world pharmaceutical priority setting on national, regional and local level in Sweden and internationally for several year, the conclusion reached in my doctorial thesis was that there are a few contextual conditions that need to be fulfilled in order for cost-effectiveness data to be incorporated into any part of priority setting. These conditions are as following; 1) lack of budget restrictions, 2) fit between data and decision-making rules legitimate to be used by decision-makers to reduce uncertainty, 3) demand for transparency, 4) internal and external institutions, and 5) existence of a prevailing template for how to incorporate (13). This framework will be used to analyse the results derived from Eckard et al. (12).

\section{Budget restrictions}

The occurrence of budget restrictions is suggested to limit the use of cost-effectiveness data as few such evaluations inform decisions like how to optimize the budget on a healthcare department level. Due to its ability of enlighten healthcare managers with an estimated expenditure for an intervention (based on the expected unit cost and volume), budget impact analyses are speaking directly to affordability, the chief concern of health managers everywhere, and a shortcoming of formal health economic evaluations. This observation is confirmed by the case of the national guidelines for heart diseases illustrated by Eckard et al. (12), as the priority 
setting group did not have any budget restriction to take into consideration and cost-effectiveness data was used in the priority setting.

Decision-making rules used to reduce uncertainty Decision-making rules refers to the methods used to remove or reduce uncertainty and the need for structure in the priority setting process. When observing formulary committee members prioritise the pharmaceuticals to include in a formulary, I noticed quite soon that there was a connection between the strategies used to handle uncertainty and the use of cost-effectiveness data (13). A number of strategies were implemented in order to handle uncertainty; privileging one source and excluding others, delaying decisions (i.e. postponing decisions to a later meeting), delegating the decision to the prescribing physicians, calibration (standardise different sources), and sequential decisionmaking (considering different evidence at different points in time) and sequential decision-making. Cost-effectiveness data increased in importance when the calibration strategy was implemented since this was data that could be included in meta-analyses and fitted the desired strategy to reduce uncertainty. Of course it is impossible to judge if it was the data available that influenced the preference for strategy to reduce uncertainty or vice versa, but there seems to be a interdependency at hand that is worthwhile looking closer into. Also, in the Eckard et al. (12) article this link between reducing uncertainty and use of cost-effectiveness data was observed.

\section{Transparency}

When there is a demand for transparency in priority setting, it is suggested to increase the probability that health economic evaluations are used due to its relative applicability compared to other decision criteria (13). The most prominent health technology assessment agencies globally, in terms of using cost-effectiveness data, interestingly share the common feature that their decision-making process is relatively transparent and influenced by the theoretical framework "Accountability for Reasonableness" (A4R). According to this framework, fair and legitimate processes must fulfill the four conditions of publicity, relevance, revisions and enforcement (14). This framework is based on the ideas of democratic deliberation.

The publicity criterion is perceived as a guarantee for patterns to evolve in the priority setting. By informing stakeholders who are affected by the decisions, in a way which increases the understanding of the motives of the decision, the acceptance of the outcome is suggested to increase. Consequently, this transparency is thought to lead to the development of "case laws", i.e. like cases will be treated in a similar way. Why cost-effectiveness data is used particularly in those priority setting situations where there is demand for transparency may be explained by the relative simplicity of applying cost-effectiveness compared to principles such as need and solidarity. Like National Institute for Health and Care Excellence (NICE) and TLV (the Swedish Dental and Pharmaceutical Benefits Board), the National Board of Health and Welfare is adapting transparency of priority setting in a similar way so fits nicely with previous experiences that cost- effectiveness data is also used in decision-making.

\section{Internal and external institutions}

Internal and external institutions are the taken-for-granted assumptions that prevails in an organisation and part of the tacit or explicit knowledge around the values (for instance the relative importance of decision criteria), or the professional norms, underpinning the organisation or individuals influences the use through the rationalities and archetypes prevailing in the organisation. In organisations, or situations, when medical decision-makers do not base their decision on evidence, the use of cost-effectiveness data, by default, will be extremely limited. A fundamental pre-condition for use would be a preference for the rational decision-making style. If this is the case, the battle among the professions will center around what kind of information is legitimate and rational to use. Having studied priority setting from the inside observing the decision-makers in real life over time it becomes soon quite evident that different professions have their own standards and ideals they try to transfer to the organisations they belong to. However, in most organisations it is possible for multiple rationalities to co-exist and particularly so in priority setting groups. So in order to maximize the benefit for all parties involved and allowing these different standards to co-exist, maybe it is very rational to use different information in different phases of decision-making? In the case of Eckard et al. (12), the co-existence of multiple rationalities was identified as well, confirming that health economists have reached the point of being considered as a profession and thus cost-effectiveness data is legitimate to use in healthcare priority setting as long as there is someone there who has been legitimately assigned (a health economist) to translate and explain what it means and how it should be used. The constant reinforcement of including cost-effectiveness data in priority setting illustrated in the latter case also legitimized the health economist attending as a representative of a profession of importance.

\section{Prevailing templates}

In New Institutional Theory it is assumed that organisations are organised by their managers in accordance with the prevailing template in their field (15). This means that they mimic other organisations to retain legitimacy (isomorphism). Isomorphism results from both formal and informal pressure exerted on a weaker organisation by another stronger party which it is dependent upon, between two parties. The mimicking organisation aim at gaining some of that success, and hence legitimacy, by imitating the more successful organisation. In the case of the National Board of Health and Welfare, the agency share a common template for successful Health Technology Assessment (HTA) with other Swedish national authorities such as TLV and SBU (The Swedish Council of Health Technology Assessment) although these three national authorities have different areas of responsibility. All three Swedish authorities are guided by a national framework for priority setting which stipulates that the cost-effectiveness principle among other principles should form basis for priority setting decisions. So, in the Eckard et al. (12) case, there were clear instructions that costeffectiveness data should be part of the consideration and 
also other prevailing templates for how to incorporate such data into decision-making, thus legitimating the use of costeffectiveness data.

Using this framework for understanding the conditions at hand influencing a positive uptake of cost-effectiveness data in the research of Eckard et al.(12), it becomes clear that the key conditions for use in this priority setting context were: 1) clear goals and instructions that cost-effectiveness was a key principle for decision-making, and 2) the existence of a health economist who could understand and disseminate the costeffectiveness data to all the decision-makers in the group, help explain and translate the cost-effectiveness message and relevance into a language that made sense to those making the decisions.

The definition of use of cost-effectiveness data Measuring the use of cost-effectiveness data presents a number of challenges for the researcher as there is no generally accepted definition of the use of health economic evaluations. So far the use has been suggested to be defined as dissemination, recognition, understanding and/or utilising (1). Based on empirical research of the British National Health Service (NHS) decision-making, Williams (16) suggests use being defined rather as a matter of requesting, accessing, interpreting or implementing economic evaluations. Based on my own previous research of the use (13), I strongly believe the use may also be defined accordingly to the purpose of the use and consequently the phase of the priority setting process, i.e. preparation of the decision-making, hearing of expert comments/evaluation of evidence, actual decisionmaking and post-decision communication (rationalisation). Taking these different aspects of use into the consideration, maybe cost-effectiveness data is not rarely used any more even though it might not be used for rationalisation purposes. So the conclusion is that for cost-effectiveness data to be further used in priority setting decisions, 1) we health economists need to be pragmatic and accept the use as legitimate even though the data might not be used for legitimising decisions to the public, and 2) for decisionmakers responsible for designing priority setting process to make sure the conditions discussed are fulfilled to enable the use of cost-effectiveness data in real life.

Ethical issues

Not applicable.

\section{Competing interests}

Author declares that she has no competing interests.

Author's contribution

STE is the single author of the manuscript.

\section{References}

1. Coyle D. Increasing the Impact of Economic Evaluations in Health-Care Decision Making. Discussion paper 108. Centre for Health Economics, University of York, Health Economics Consortium; 1993

2. Drummond M, Cooke J, Walley T. Economic Evaluation in Health Care Decision Making: Evidence from the UK. Discussion paper 148. Centre for Health Economics, University of York, Health Economics Consortium; 1996.

3. Späth HM, Charavel M, Morelle M, Carrere MO. A qualitative approach to the use of economic data in the selection of medicines for hospital formularies: a French survey. Pharm World Science 2003 25: 269-75. doi: 10.1023/b:phar.0000006523.22131.69

4. McDonald R. Using Health Economics in Health Services. Rationing Rationally? Buckingham: Open University Press; 2002

5. Suh DC, Okpara IR, Agnese WB, Toscani M. Application of Pharmacoeconomics to Formulary Decision Making in Managed Care Organizations. Am J Manag Care 2002; 8: 161-9.

6. Van Velden ME, Severens JL, Novak A. Economic Evaluations of Healthcare Programmes and Decision Making. Pharmacoeconomics 2005; 23: 1075-82. doi: 10.2165/00019053200523110-00002

7. Walkom E, Robertson J, Newby D, Pillay T. The role of pharmacoeconomics in formulary decision-making. Considerations for hospital and managed care pharmacy and therapeutics committees. Formulary 2006 41: 374-86.

8. Williams I, Bryan S, Mclver S. The use of health economic evaluations in NHS decision-making. A review and empirical investigation. Health Technology Assessment 2008; 12(7). Available from: http://www.journalslibrary.nihr.ac.uk/hta/ volume-12/issue-7\#

9. Eddama $\mathrm{O}$, Coast J. A systematic review of the use of economic evaluation in local decision-making. Health Policy 2008; 86: 12941. doi: 10.1016/j.healthpol.2007.11.010

10. Vourenkoski L, Toivaninen $\mathrm{H}$, Hemminki E. Decision-making in priority setting for medicines - A review of empirical studies. Health Policy 2008; 86: 1-9. doi: 10.1016/j.healthpol.2007.09.007

11. Anell A. Priority setting for pharmaceuticals. The use of health economic evidence by reimbursement and clinical guidance committees. Eur J Health Econ 2004; 5: 28-35. doi: 10.1007/ s10198-003-0195-0

12. Eckard N, Janzon M, Levin LA. Use of cost-effectiveness data in priority setting decisions: experiences from the national guidelines for heart diseases in Sweden. Int $\mathrm{J}$ Health Policy Manag 2014; 3: 323-32. doi: 10.15171/ijhpm.2014.105

13. Erntoft $S$. The use of health economic evaluations in pharmaceutical priority setting. The case of Sweden [Doctoral dissertation]. Lund Business Press, Lund Institute of Economic Research, Lund University; 2010.

14. Daniels N, Sabin J. Limits to Health Care: Fair Procedures, Democratic Deliberation, and the Legitimacy Problem for Insurers. Philos Public Aff 1997; 26: 302-50. doi: 10.1111/j.10884963.1997.tb00082.x

15. DiMaggio P, Powell WW. The iron cage revisited: Institutional Isomorphism and Collective Rationality in Organizational Fields. Am Soc Rev 1983; 48: 147-60. doi: 10.2307/2095101

16. Williams I. Cost-effectiveness analysis and technology coverage decision making: the case of the English NHS [Doctoral dissertation]. Health Services Management Centre, School of Social Policy, University of Birmingham; 2009. 